\title{
Multivariate Analysis and its Application for Screening Mungbean [Vigna radiata (L.) Wilczek] Landraces
}

Berk Benlioglu, Ugur Ozkan

10.18805/LRF-661

\begin{abstract}
Background: Mungbean [Vigna radiata (L.) Wilczek] is known as one of the important crop of the Vigna group. In order to determine morphological traits of mungbean, multivariate analysis will provide important advantages in the selection phase of future breeding programs. Multivariate statistical analysis was used to determine and classify these traits. Multivariate analysis, that includes principal component analysis (PCA) and cluster analysis (CA), is considered the best tool for selecting promising genotypes in the future breeding programs.

Methods: Eighteen landraces and two species were used to classify morphological traits in this study. Nine different morphological traits were observed during the research period. These are; days to $50 \%$ flowering (DFT), plant height (PH), branches per plant (BPP), clusters per plant (CPP), number of pods per cluster (PPC), seed yield per plot (SYPP), biomass yield per plot (BYPP), harvest index (HI), 1000 seed weight (SW).

Result: Principal component analysis (PCA) revealed a high level of variation among the genotypes. Therefore, high variability was observed in DFT (36-59 day), PH (39-76 cm), BPP (3-7), CPP (4-21), SYPP (231-824 g), BYPP (3300-10300 g), HI (6.77-11.25\%) and $1000 \mathrm{SW}(19.95-50.50 \mathrm{~g})$. According to cluster analysis, landraces with the least genetic diversity distance between them in terms of morphological traits examined were determined as 2 and 3.

Key words: Cluster analysis, Green gram, Phenotypic characterization, Principal component analysis, Yield components.
\end{abstract}

\section{INTRODUCTION}

Mungbean [Vigna radiata (L.) Wilczek] is economically the most important crop of Vigna group. It is also known as green gram, gold gram, moong (Mehandi et al. 2019). It is a diploid $(2 n=2 x=22)$, self-pollinating grain legume belonging to Fabaceae family.

The agronomic significance of mungbean is linked to its high protein percentage and minerals, especially micronutrients. It has wide adaptability, relatively less need for water compared to other legumes (Parida and Das, 2005) and low input costs in production, high protein content (22$28 \%$ ) and nutritional value (Singh and Singh, 2011).

For moderately fertile soils, mungbean is a suitable crop due to its nitrogen-fixing ability and has a short growing period with drought tolerance (Shil and Bandopadhyay 2007). Therefore, mungbean has better digestibility compared to other pulses (Tabasum et al. 2010).

Mungbean is potentially used to improve cropping systems and it can be grown almost throughout the year. Mungbean play important roles as supplements of animal feeds. Mungbean is grown as green manure, hay, a cover crop and for forage (Akpapunam, 1996). Its seeds are rich in protein which is nearly three times as much as cereals (Thirumaran and Seralathan, 1988). Mungbean seeds are also rich in carbohydrates, fibers, minerals, antioxidants like flavonoids (Quercetin-3-O-glucoside) and phenolics (Guo et al. 2012). When supplemented with cereals, the perfect mix of essential amino acids with high biological value might be obtained. Due to its positive benefits; mungbean is an inseparable ingredient in the diet of a vast majority of
Department of Field Crops, Faculty of Agriculture, Ankara University, 06110-Diskapi, Ankara, Turkey.

Corresponding Author: Ugur Ozkan, Department of Field Crops, Faculty of Agriculture, Ankara University, 06110-Diskapi, Ankara, Turkey. Email: ugurozkan@ankara.edu.tr

How to cite this article: Benlioglu, B. and Ozkan, U. (2022). Multivariate Analysis and its Application for Screening Mungbean [Vigna radiata (L.) Wilczek] Landraces. Legume Research. DOI: $10.18805 /$ LRF-661.

Submitted: 22-10-2021 Accepted: 18-12-2021 Online: 06-01-2022

populations in the World, especially rural societies of developing countries (Mehandi et al. 2019). Green pods and seeds can be cooked as vegetables. Thus, this plant is recognized as poor people's meat (Singh et al. 2018).

Morphological traits are routinely used for predicting genetic variability screening and genetic relationships among the genotypes (Pandey, 2007). Nair et al. (2012) have indicated that future prospects in mungbean breeding require obligatory action to screen mungbean genotypes with favorable agronomic characters for further improvement programs. Screening of genetic diversity needs extensive statistical analysis like multivariate analysis which is including principal component analysis (PCA) and cluster analysis (CA). These analyses are considered the best tools for choosing promising genotypes in future breeding programs of mungbean. The main advantage of using PCA over CA is that each genotype may be assigned to one group (Mohammadi, 2002). Except for these analyses, correlation 
analysis provides the knowledge among important plant characters. It also leads to a directional model for direct or indirect improvement in grain yield (Khan and Khalil, 2004). The goal of the study is to screen mungbean landraces based on morphologic traits using multivariate analysis and to define a set of agronomic attributes to be used in future mungbean breeding program.

\section{MATERIALS AND METHODS}

Eighteen landraces and two species were evaluated for various morphological traits in an randomized block design with triplicate replication at Edremit, Balıkesir during April to September 2020 located at a latitude $39^{\circ} 35^{\prime \prime} \mathrm{N}$, longitude $27^{\circ} 2$ "E and elevation $16 \mathrm{~m}$ above sea level. During the research period (April to September); total rainfall, average temperature and relative humidity were $155.3 \mathrm{~mm}, 22.6^{\circ} \mathrm{C}$ and 89.2 per cent, respectively. The landraces and their locations are presented in Table 1. Also, the names of two species used are Kalkinis (No. 99) and Parlov (No. 100).

The individual plot size was $3 \mathrm{~m}^{2}(1.5 \mathrm{~m} \times 2 \mathrm{~m})$. There were 6 rows in each plot. The row spacing of the individual plants was $30 \mathrm{~cm}$. Thus, the total area of the research plots was $180 \mathrm{~m}^{2}$. Nine different morphological traits were observed during the research period. These are; days to $50 \%$ flowering time (DFT), plant height $(\mathrm{PH})$, branches per plant (BPP), clusters per plant (CPP), number of pods per cluster (PPC), seed yield per plot (SYPP), biomass yield per plot (BYPP), harvest index (HI), 1000 seed weight (SW). Days to flowering were recorded at $50 \%$ of flowering. Plant height $(\mathrm{cm})$, branches per plant, clusters per plant, 1000 seed weight $(\mathrm{g})$ were recorded on randomly sampled 10 plants. Seed yield $(\mathrm{g})$ and biomass yield $(\mathrm{g})$ were calculated in each plot. Harvest index was determined as seed yield expressed as a percentage of biomass yield.

The data recorded were then subjected to determine simple statistics predictions, i.e., mean, minimum and maximum value of each trait, standard deviations and coefficient variation. Morphological traits were analyzed as multivariate by using procedures of principal component analysis (PCA) and cluster analysis (CA) with the help of computer software "JMP" v 13.0 (SAS, 2017). PCA was accomplished using a correlation matrix in order to reveal the relationship among quantitative traits that are correlated among each other by converting them into uncorrelated traits called PCs (Johnson and Wichern, 1988). PCA provided information about the relative importance of each trait for screening the landraces in this study. The other multivariate analysis, most widely used clustering technique, hierarchical clustering was used to determine similarity and dissimilarity in the landraces. CA was designed on the average distance k-means and landraces in each cluster were then analyzed for basic statistics.

\section{RESULTS AND DISCUSSION}

The results of simple descriptive statistics including mean value, maximum value, minimum value, standard deviation (SD) and coefficient of variation (CV) of the investigated morphologic traits studied in mungbean landraces are presented in Table 2. Statistical analysis of the obtained data revealed that a wide range of variables in morphological traits. High variability in DFT (36-59 day), PH (39-76 cm), BPP (3-7), CPP (4-21), SYPP (231-824 g), BYPP (3300$10300 \mathrm{~g}), \mathrm{HI}(6.77-11.25 \%)$ and $1000 \mathrm{SW}(19.95-50.50 \mathrm{~g})$ was detected among the morphologic traits (Table 2).

The landrace 21 had the maximum value in terms of $\mathrm{PH}, \mathrm{BPP}, \mathrm{CPP}$ and PPC traits. In addition to this, it reached DFT the earliest. Landrace 1 had the lowest value in $\mathrm{PH}$, BPP, CPP, PPC and SYPP parameters (Table 2).

The data were subjected to correlation analysis to determine relationships between the examined morphologic traits. According to correlation analysis, the highest relationship was found between SYPP to BYPP (0.960) in all morphologic traits. On the other hand, the highest negative relationship was observed between DFT and $\mathrm{HI}$ $(-0.206)$ (Table 3).

Principal component analysis (PCA) revealed a high level of variation among the genotypes. The variation studied with principal component analysis showed that two principal components having greater than one eigenvalue contributed $80.57 \%$ of the total variance among the nine variable morphological traits (Table 4). At $p \leq 5 \%, \mathrm{PH}, \mathrm{CPP}$, SYPP and BYPP were the main contributors to the first principle component which made up $65.08 \%$ of the total variation. However, DFT had the lowest and negative contribution for the observed variations in PC1. On the contrary, main contributor of the second principal component, which is

Table 1: Mungbean landraces ant its locations.

\begin{tabular}{llcl}
\hline Landraces & Location & Landraces & Location \\
\hline 1 & Adiyaman-Gumuskasik 1 & 27 & Gaziantep-Sahinbey \\
2 & Adiyaman-Gumuskasik 2 & 44 & Mersin-Anamur \\
3 & Adiyaman-Guzelsu 1 & 59 & Konya-Meram 1 \\
5 & Adiyaman-Kutuklu 1 & 67 & Nevsehir-Merkez \\
12 & Antalya-Ugrak & 79 & Karaman-Daran \\
15 & Antalya-Doganca & 81 & Karaman-Dumlugoze \\
20 & Antalya-Zeytinada 1 & 91 & Kilis-Merkez \\
21 & Antalya-Zeytinada 2 & 96 & Uzbekistan 1 \\
24 & Gaziantep-Nizip & 98 & Uzbekistan 2 \\
\hline
\end{tabular}


responsible for $15.50 \%$ of the total variation was DFT, PPC, $\mathrm{HI}$ and SYPP but contributed negatively to PC2. The first two principal components which contributed to $80.57 \%$ of the total variance were plotted graphically to show the similarities among landraces (Fig 1). The graph was designed by computing each feature individually to separate landraces. The graph withal showed the variability of landraces for the nine morphological traits in the study. It can be concluded that there exists wide genetic variability among the landraces based on the distribution model of the landraces on the graph.

Table 2: Genetic variable parameters for morphologic traits of mungbean landraces.

\begin{tabular}{lccccccc}
\hline Characters & Mean & Minimum & Genotype & Maximum & Genotype & SD & CV \\
\hline DFT (day) & 45.80 & 36 & 21 & 59 & 79 & 5.95 & 13.00 \\
PH (cm) & 55.42 & 39.00 & 1 & 76.00 & 21 & 12.04 & 21.73 \\
BPP & 4.67 & 3 & $1,3,5,27,79,81,91,96,98$ & 7 & $21,24,99,100$ & 1.30 & 27.80 \\
CPP & 10.73 & 4 & $1,81,96$ & 20 & 21 & 4.27 & 39.75 \\
PPC & 10.02 & 7 & $1,27,59,81$ & 15 & 21 & 2.06 & 20.59 \\
SYPP (g) & 523.38 & 231.00 & 1,79 & 824.00 & 24 & 176.05 & 33.64 \\
BYPP (g) & 6074.80 & 3300.00 & 81 & 10300.00 & 44 & 2044.36 & 33.65 \\
HI (\%) & 8.62 & 6.77 & 79 & 11.25 & 3 & 1.01 & 11.76 \\
1000 SW (g) & 34.66 & 19.95 & 2 & 50.50 & 100 & 8.73 & 25.18 \\
\hline
\end{tabular}

SD: standard deviation, CV: coefficient of variation, days to $50 \%$ flowering (DFT), plant height (PH), branches per plant (BPP), clusters per plant (CPP), number of pods per cluster (PPC), seed yield per plot (SYPP), biomass yield per plot (BYPP), harvest index (HI), 1000 seed weight $(\mathrm{SW})$.

Table 3: Correlation coefficients of morphological traits in mungbean landraces.

\begin{tabular}{lccccccccc}
\hline Characters & DFT & PH & BPP & CPP & PPC & SYPP & BYPP & HI & 1000 SW \\
\hline DFT & - & -0.080 & -0.119 & -0.094 & -0.114 & -0.202 & -0.166 & -0.206 & 0.070 \\
PH & & - & 0.707 & 0.841 & 0.634 & 0.893 & 0.917 & -0.014 & 0.672 \\
BPP & & - & 0.737 & 0.566 & 0.743 & 0.751 & 0.047 & 0.560 \\
CPP & & & - & 0.642 & 0.873 & 0.904 & -0.019 & 0.627 \\
PPC & & & & - & 0.675 & 0.682 & 0.061 & 0.320 \\
SYPP & & & & & & - & 0.960 & 0.256 & 0.585 \\
BYPP & & & & & & & - & -0.012 & 0.614 \\
HI & & & & & & & -0.107 \\
1000 SW & & & & & & & & & -
\end{tabular}

Days to $50 \%$ flowering (DFT), plant height (PH), branches per plant (BPP), clusters per plant (CPP), number of pods per cluster (PPC), seed yield per plot (SYPP), biomass yield per plot (BYPP), harvest index (HI), 1000 seed weight (SW).

Table 4: Principal component analysis of morphological variation of mungbean landraces. Eigenvectors and eigenvalues of the principal components, total variance and cumulative variance for morphological traits.

\begin{tabular}{lccccccccc}
\hline Principle components & PC 1 & PC 2 & PC 3 & PC 4 & PC 5 & PC 6 & PC 7 & PC 8 & PC 9 \\
\hline Eigenvalue & 5.86 & 1.39 & 0.76 & 0.53 & 0.24 & 0.14 & 0.06 & 0.03 & 0.00 \\
Variance (\%) & 65.08 & 15.50 & 8.40 & 5.86 & 2.70 & 1.57 & 0.61 & 0.28 & 0.02 \\
Cumulative (\%) & 65.08 & 80.57 & 88.97 & 94.83 & 97.53 & 99.09 & 99.70 & 99.99 & 100.00 \\
Component matrix & & & & & & & & & \\
DFT & -0.069 & 0.607 & 0.764 & -0.158 & -0.124 & -0.005 & -0.043 & -0.034 & -0.005 \\
PH & 0.398 & 0.087 & -0.025 & 0.012 & -0.295 & -0.101 & 0.840 & 0.166 & 0.062 \\
BPP & 0.388 & 0.012 & 0.044 & 0.046 & 0.196 & -0.865 & -0.191 & -0.148 & 0.013 \\
CPP & 0.403 & 0.051 & -0.037 & 0.013 & -0.282 & 0.082 & -0.430 & 0.748 & -0.058 \\
PPC & 0.337 & -0.126 & 0.124 & -0.604 & 0.645 & 0.228 & 0.096 & 0.117 & 0.003 \\
SYPP & 0.400 & -0.151 & 0.088 & -0.008 & -0.243 & 0.209 & -0.094 & -0.425 & -0.719 \\
BYPP & 0.404 & 0.001 & -0.058 & -0.114 & -0.284 & 0.241 & -0.226 & -0.430 & 0.668 \\
HI & 0.023 & -0.682 & 0.621 & 0.328 & 0.008 & 0.027 & 0.048 & 0.099 & 0.169 \\
1000 SW & 0.296 & 0.343 & -0.023 & 0.698 & 0.474 & 0.283 & 0.019 & -0.036 & 0.022 \\
\hline
\end{tabular}

Days to $50 \%$ flowering (DFT), plant height (PH), branches per plant (BPP), clusters per plant (CPP), number of pods per cluster (PPC), seed yield per plot (SYPP), biomass yield per plot (BYPP), harvest index (HI), 1000 seed weight (SW). 
Cluster analysis was made to identify the genetic relationship among the genotypes and determine the appropriate genotypes for future breeding programs. The characterization of diversity in parents must be vital for better breeding programs of the new tolerant varieties. Cluster analysis based on nine morphological traits for 20 landraces classified hierarchically with Wards linkage clustering method them into five separate and well-defined clusters (Table 5). According to cluster analysis, landraces with the least genetic diversity distance between them in terms of morphological traits examined were determined as 2 and 3 . These landraces are included in Cluster 2. The landraces with the furthest genetic diversity distance between them were 1 and 100 (Fig 2). Cluster 5, Cluster 3 comprised four landraces which were high properties for $\mathrm{PH}, \mathrm{BPP}, \mathrm{CPP}$, PPC, SYPP, BYPP and 1000 SW. With these traits, the landraces grouped in Cluster 3 attract attention. Classification of landraces into the phenotypically similar cluster of different groups is beneficial for selecting parents for hybridization. Cluster analysis grouped the mungbean landraces with greater phenotypic similarity Although the clusters might not always involve all the accessions from the source of the same or adjacent sites. Hence, landraces obtained from the same site were in the same cluster and in different clusters in this study.

Variation is one of the most important requirements for selection phase in plant breeding (Canci and Toker, 2014). Bosang and Caligari (1995) remarked that more genetic variation in traits that are examined about the characters is more genetic gain. Wide variation has been reported in mungbean with respect to growth, phenology, yield components and grain yield (Yimram et al. 2009). In this study, high variability was specified in morphological traits. The importance of multivariate analysis is high in connection with the grouping of the mungbean landraces based on morphologic traits in this study. Falcinelli et al. (1988) indicated that multivariate analysis, which is included principal component analysis and hierarchically cluster method, to be the valid system to deal with germplasm collection.

Abna et al. (2012) studied 20 mungbean genotypes and reported that the first three principal components together performed $78.34 \%$ of the total variation. In this study, the first three principal components made up $88.97 \%$ of the total variation. In our study, the main contributor of the first principal component, which accounts for the highest part of

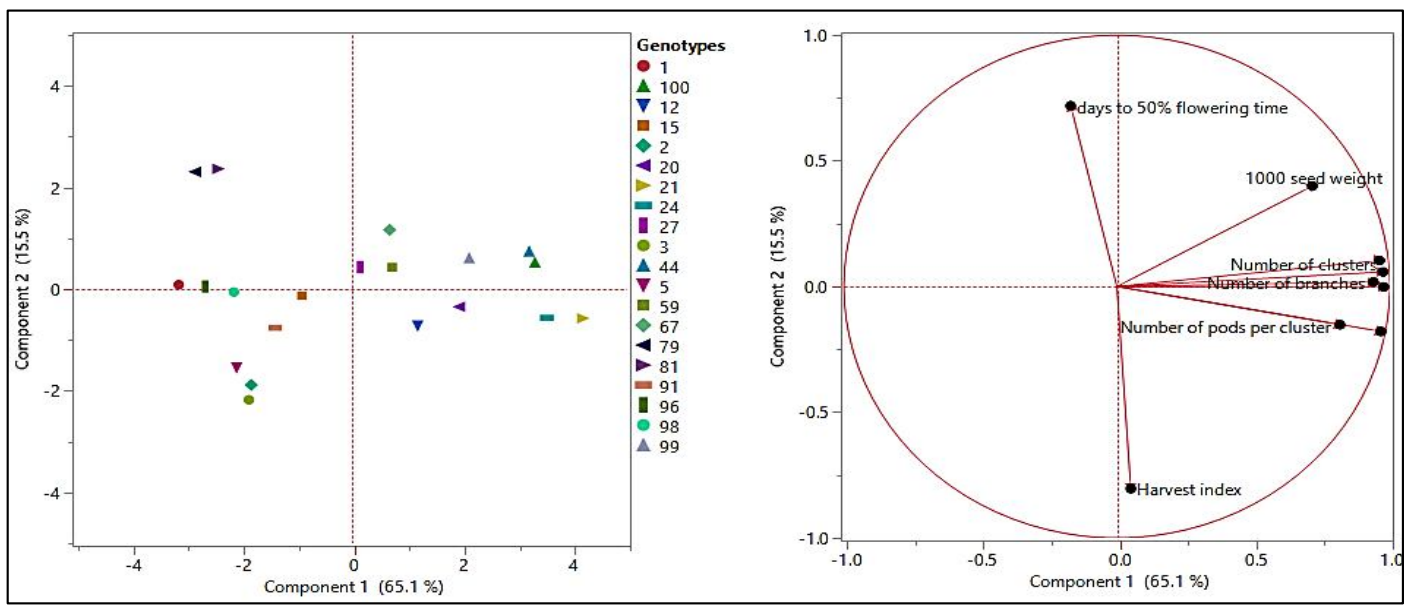

Fig 1: Classification of mungbean landraces along the first and second principal components based on characterization of morphological traits.

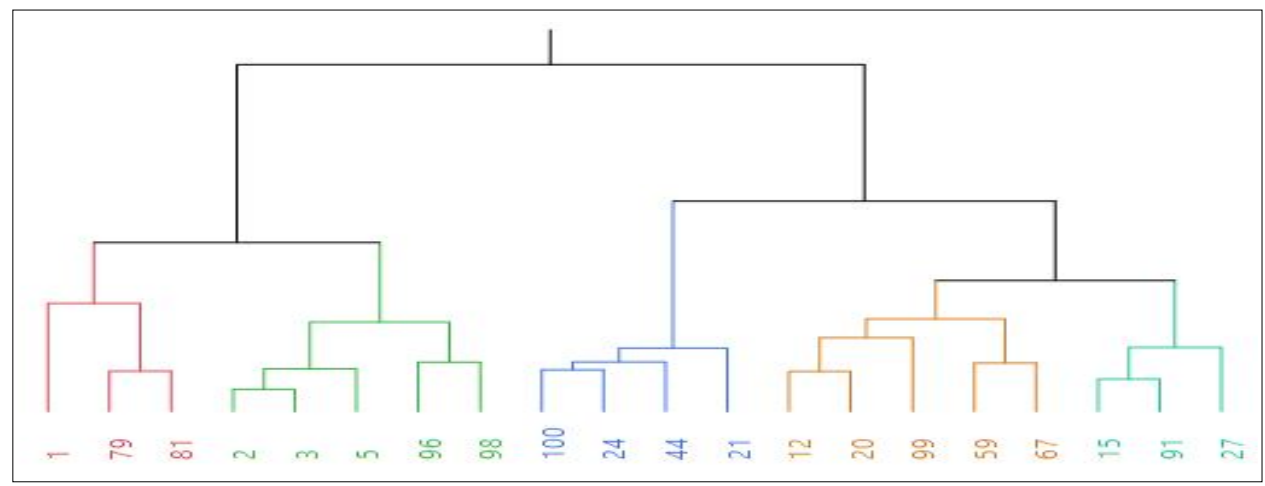

Fig 2: Phylogenetic tree for 20 landraces of mungbean for morphologic traits. 
Multivariate Analysis and its Application for Screening Mungbean [Vigna radiata (L.) Wilczek] Landraces

Table 5: Cluster means for analyzed parameters in mungbean landraces.

\begin{tabular}{lcccccccccc}
\hline Cluster & Count & DFT (day) & PH $(\mathrm{cm})$ & BPP & CPP & PPC & SYPP $(\mathrm{g})$ & BYPP $(\mathrm{g})$ & $\mathrm{HI}(\%)$ & $1000 \mathrm{SW}(\mathrm{g})$ \\
\hline 1 & 3 & 49.56 & 44.33 & 3.56 & 6.33 & 8.33 & 262.89 & 3707.22 & 7.08 & 30.18 \\
2 & 5 & 45.93 & 43.80 & 3.73 & 7.00 & 9.53 & 417.33 & 4383.33 & 9.51 & 23.39 \\
3 & 4 & 45.08 & 70.75 & 6.08 & 16.33 & 13.17 & 774.33 & 9074.50 & 8.56 & 42.54 \\
4 & 5 & 46.27 & 64.80 & 5.47 & 12.93 & 9.80 & 618.07 & 7156.60 & 8.67 & 39.26 \\
5 & 3 & 42.00 & 49.78 & 4.11 & 10.22 & 8.67 & 468.22 & 5458.89 & 8.66 & 39.77 \\
\hline
\end{tabular}

Days to $50 \%$ flowering (DFT), plant height (PH), branches per plant (BPP), clusters per plant (CPP), number of pods per cluster (PPC), seed yield per plot (SYPP), biomass yield per plot (BYPP), harvest index (HI), 1000 seed weight (SW).

the total variation, was the "number of clusters", while Abna et al. (2012), stated that the main contributor of the firt principal component was the "number of clusters". Zubair et al. (2007) stated that principal components with an eigenvalue greater than 1 constitute $85.49 \%$ of the total variation and that the first principal component is more related to yield traits, while the second principal component is related to maturation time. Results show significant similarities with these results in this study. Principal components with an eigenvalue greater than 1 accounted for $80.57 \%$ of the total variation. The first principal component was more related to the biomass per plot, the number of clusters, seed yield per plot and plant height parameters, while the second principal component was the number of days to $50 \%$ flowering found to be more relevant to.

The days to $50 \%$ flowering time varied from 36 to 59 days in this study. However, Canci and Toker (2014) indicated that this period is between 20 to 76 days. In previous studies, the plant height range of mungbean landraces was reported by Abna et al. (2012) 26.9-57.0 cm, Canci and Toker (2014) 19.5-91.0 cm, Peksen et al. (2015) $39.95-72.08 \mathrm{~cm}$, Patel et al. (2019) $51.88-94.07 \mathrm{~cm}$, Ton (2021) 60.8-71.3 cm. Mungbean landraces plant height varied from 39.00 to $76.00 \mathrm{~cm}$. The number of branches of genotypes varied between 3 and 7 . Similarly, Canci and Toker (2014) demonstrated that the number of branches in mungbean landraces is between 2 and 6 . Even though Abna et al. (2012) and Begum et al. (2012) reported that this number is between 1 and 3.5 and 2.25 and 4.25 , in the same vein. It was observed that the number of clusters was a minimum 4 and a maximum of 20 in this study. It has been documented by previous studies that the number of clusters per plant showed a large variation [(Abna et al. (2012) 3.213.5; Singh et al. (2011) 18.8-29.4; Taj et al. (2003) 10-23, Canci and Toker (2014) 8.0-62.5 and Ton (2021) 16.4-62.5)]. It can be interpreted that this wide variation occurs as a result of the interaction of genetic structure and environmental factors.

The range of seed yield of mungbean landraces was documented by Taj et al. (2003), Singh et al. (2011), Canci and Toker (2014), Gul et al. (2019), Ahmad and Belwal (2020), Ton (2021); as 366.25-503.50 kg/ha; $1151-2424 \mathrm{~kg} /$ ha, 33.3-3916.6 kg/ha, 56.6-711.7 kg/ha, 333.3-5916.7 kg/ ha, $2093-3816 \mathrm{~kg} / \mathrm{ha}$, in the same order. Mungbean landraces seed yield varied $770.0-2746.6 \mathrm{~kg} / \mathrm{ha}$. The range of biological yield of mungbean landraces was stated by Canci and Toker (2014) 683-42000 kg/ha; Gul et al. (2019) $420.5-4286.0 \mathrm{~kg} / \mathrm{ha}$. Mungbean landraces biological yield varied $11000-34333 \mathrm{~kg} / \mathrm{ha}$. 1000 seed weight of mungbean landraces was reported by Taj et al. (2003), Zubair et al. (2007), Abna et al. (2012), Singh et al. (2011), , Begum et al. (2012), Canci and Toker (2014), Peksen et al. (2015), Gul et al. (2019), Ahmad and Belwal (2020) and Ton (2021); as 24.0130.72 g, 20.0-47.8 g, 24.0-50.0 g, 37.5-57.4 g, 32.2-58.5, $31.0-86.0 \mathrm{~g}, 31.0-81.6 \mathrm{~g}, 35.72-70.64 \mathrm{~g}, 22.0-58.5 \mathrm{~g}$ and $50.7-$ $77.1 \mathrm{~g}$, respectively. Similarly in this study, 1000 seed weights varied from 19.95 to $50.50 \mathrm{~g}$. The harvest index of mungbean landraces varied from 6.77 to $11.25 \%$. Similarly, Zubair et al. (2007) noted that the harvest index is between 6.86 and 22.48\%. However, Peksen et al. (2015) and Gul et al. (2012) reported that the harvest index is between 16.85 and $22.48 \%$ and 13.3 and $37.3 \%$, in the same vein.

Canci and Toker (2014) noted that the highest correlation value occurred between biological yield and straw yield $(r=0.989)$. Similarly, the highest correlation occurred between biological yield and seed yield $(r=0.960)$ in this study. Zubair et al. (2007) stated that there was a negative correlation between flowering time and number of branches, the number of clusters, the number of pods in cluster, seed yield and biomass parameters. Hence, the correlation between the days to $50 \%$ flowering and the above parameters was found to be negative.

\section{CONCLUSION}

The results of this study show that there is significant and wide variation in most of the agro-morphological traits studied in mungbean landraces. By way of the developement and definement of plant genetic diversity, the breeding of new varieties are facilitated as a result of the selection and crossbreeding of parents with desired characteristics. Determining the differences and similarities in the genotypes through multivariate analyzes, it provides a great advantage in making selections for the demanded traits. With the results obtained from this study; it can be interpreted that landrace 21, 24, 44 and Parlov (No.100) are superior to other genotypes in terms of phenotypic characteristics examined. Additionally, it is possible that these genotypes have different origins and that there are differences. Therefore, these genotypes should be tested in different ecological conditions. 


\section{REFERENCES}

Abna, F., Golam, F., Bhassu, S. (2012). Estimation of genetic diversity of mungbean [Vigna radiata (L.) Wilczek] in Malaysian tropical environment. African Journal of Microbiology Research. 6(8): 1770-1775.

Akpapunam, M. (1996). Mung bean [Vigna radiata (L.) Wilczek]. In Food and Feed from Legumes and Oilseeds, Springer, Boston, MA. (pp. 209-215).

Ahmad, S. and Belwal, V. (2020). Morphological characterization and evaluation of mungbean [Vigna radiate (L.) Wilczek] germplasm for various yield attributing traits. Int. J. Curr. Microbiol. App. Sci. 9(1): 780-790.

Begum, S., Noor, M., Hassan, G., Rahman, H.U., Durrishawar, Ullah, H., Jan, M. (2012). Genotypic association among yield and related attributes in mungbean genotypes. International Research Journal of Agricultural Science and Soil Science. 2(5): 188-193.

Bos, I. and Caligari, P. (1995). Selection Methods in Plant Breeding. Published by Chapman and Hall, 2-6 Boundary Row, London, SE1 8HN, UK.

Canci, H. and Toker, C. (2014). Yield components in mung bean [Vigna radiata (L.) Wilczek]. Turkish Journal of Field Crops. 19(2): 258-261.

Falcinelli, M., Veronesi, F., Lorenzetti, S. (1988). Evaluation of An Italian Germplasm Collection of Lolium perenne L. through A Multivariate Approach. In Proceedings of the Eucarpia Fodder Crops Section Meeting, Lusignan, France. pp 2335.

Gul E., Anlarsal, A.E., Bicer, B.T. (2019). The effect of different sowing densities on the yield and yield component of some mung bean [Vigna radiata (L.) Wilczek] cultivars in Diyarbakır Ecological Conditions. Cukurova University Journal of Natural and Applied Sciences. 38(1): 94-105.

Guo, X., Li, T., Tang, K., Liu, R.H. (2012). Effect of germination on phytochemical profiles and antioxidant activity of mung bean sprouts (Vigna radiata). Journal of Agricultural and Food Chemistry. 60(44): 11050-11055.

Johnson, R.A. and Wichern, D.W. (1988). Applied Multivariate Statistical Analysis. $2^{\text {nd }}$ Edition, John Wiley and Sons Inc., New York.

Khan, M.D. and Khalil, I.H. (2004). Genetic divergence and association for yield and related traits inmash bean. Sarhad Journal of Agriculture. 20(4): 555-561.

Mehandi, S., Quatadah, S., Mishra, S.P., Singh, I., Praveen, N. and Dwivedi, N. (2019). Mungbean [Vigna radiata (L.) wilczek]: Retrospect and prospects. Legume CropsCharacterization and Breeding for Improved Food Security, ed. El-Esawi MA (London: IntechOpen, 49-66).

Mohammadi, S.A. (2002). Statistical Methods in Genetics. Paper presented at the $6^{\text {th }}$ Int. Conf. of Statistics, University of Tarbiat modares, Iran.

Nair, R.M., Schafleitner, R., Kenyon, L., Srinivasan, R., Easdown, W., Ebert, A.W., Hanson, P. (2012). Genetic improvement of mungbean. SABRAO Journal of Breeding and Genetics. 44(2): 177-190.
Pandey, M.K., Srivastava, N., Kole, C.R. (2007). Selection strategy for augementation of seed yield in mungbean [Vigna radiata (L.) Wilczek]. Legume Research-An International Journal. 30(4): 243-249.

Parida, A.K. and Das, A.B. (2005). Salt tolerance and salinity effects on plants: A review. Ecotoxicology and Environmental Safety. 60: 324-349.

Patel, J.D., Patel, J.B., Chetariya, C.P. (2019). Characterization of mung bean [Vigna radiata (L.) Wilczek] genotypes Based on Plant Morphology, Ind. J. Pure App. Biosci. 7(5): 433443. doi: http://dx.doi.org/10.18782/2320-7051.7793.

Peksen, E., Toker, C., Ceylan, F.O., Aziz, T., Farooq, M. (2015). Determination of promising high yielded mungbean [Vigna radiata (L.) Wilczek] genotypes under Middle Black Sea Region of Turkey. Anadolu Journal of Agricultural Sciences. 30(2): 169-175.

SAS Institute Inc (2017). JMP ${ }^{\circledR}$ Statistical Discovery Software, version 13.0; - SAS Institute Inc., Cary, NC.

Shil, S. and Bandopadhyay P.K. (2007). Retaining seed vigor and viability of mungbean by dry dressing treatments. Journal of Food Legumes 20: 173-75.

Singh, D.P. and Singh, B.B. (2011). Breeding for tolerance to abiotic stresses in mungbean. Food Legumes. 24(2): 83-90.

Singh, G., Sekhon, H.S., Singh, G., Brar, J.S., Bains, T.S., Shanmugasundaram, S. (2011). Effect of plant density on the growth and yield of mungbean genotypes under different environments in India and Taiwan. International Journal of Agricultural Reserach. 6: 573-583.

Singh, R., Van Heusden, A.W,. Kumar R., Visser, R.G.F. (2018). Genetic variation and correlation studies between micronutrient ( $\mathrm{Fe}$ and $\mathrm{Zn}$ ), protein content and yield attributing traits in mungbean (Vigna radiata L.). Legume Research 41: 167-74. doi: 10.18805/Ir.v0i0.7843.

Tabasum, A., Saleem M., Aziz, I. (2010). Genetic variability, trait association and path analysis of yield and yield components in mungbean [Vigna radiata (L.) Wilczeek]. Pakistan Journal of Botany. 42: 3915-24.

Taj, F.H., Arif, M., Kakar, K.M. (2003). Effect of seed rates on mungbean varieties under dryland conditions. International Journal of Agriculture and Biology. 5(2): 160-161

Thirumaran, A.S. and Seralathan, M.A. (1988). Utilization of mungbean. International Symposium on Mungbean, $2^{\text {nd }}$ Bangkok Nov 16-20. p.470-485, Thailand.

Ton, A. (2021). Agro-morphlogical and Quality Characters in two Summer Legume Crops: Mung Bean [Vigna radiata (L.) Wilczek] and Guar [Cyamopsis tetragonoloba (L.) Taub] genotypes grown in mediterranean climate conditions. Legume Research. 44(9): 1072-1076. DOI: 10.18805/LR-618.

Yimram, T., Somta, P., Srinives, P. (2009). Genetic variation in cultivated mungbean germplasm and its implication in breeding for high yield. Field Crops Research. 112(2-3): 260-266.

Zubair, M., Ajmal, S.U., Anwar, M., Haqqani, A.M. (2007). Multivariate analysis for quantitative traits in mungbean [Vigna radiata (L.) Wilczek]. Pakistan Journal of Botany. 39(1): 103. 